Document downloaded from:

http://hdl.handle.net/10251/56782

This paper must be cited as:

López Navarro, A.; Biosca Taronger, J.; Torregrosa Jaime, B.; Corberán Salvador, JM.; Bote García, J.; Payá Herrero, J. (2013). Experimental investigations on the influence of ice floating in an internal melt ice-on-coil tank. Energy and Buildings. 57:20-25. doi:10.1016/j.enbuild.2012.10.040.

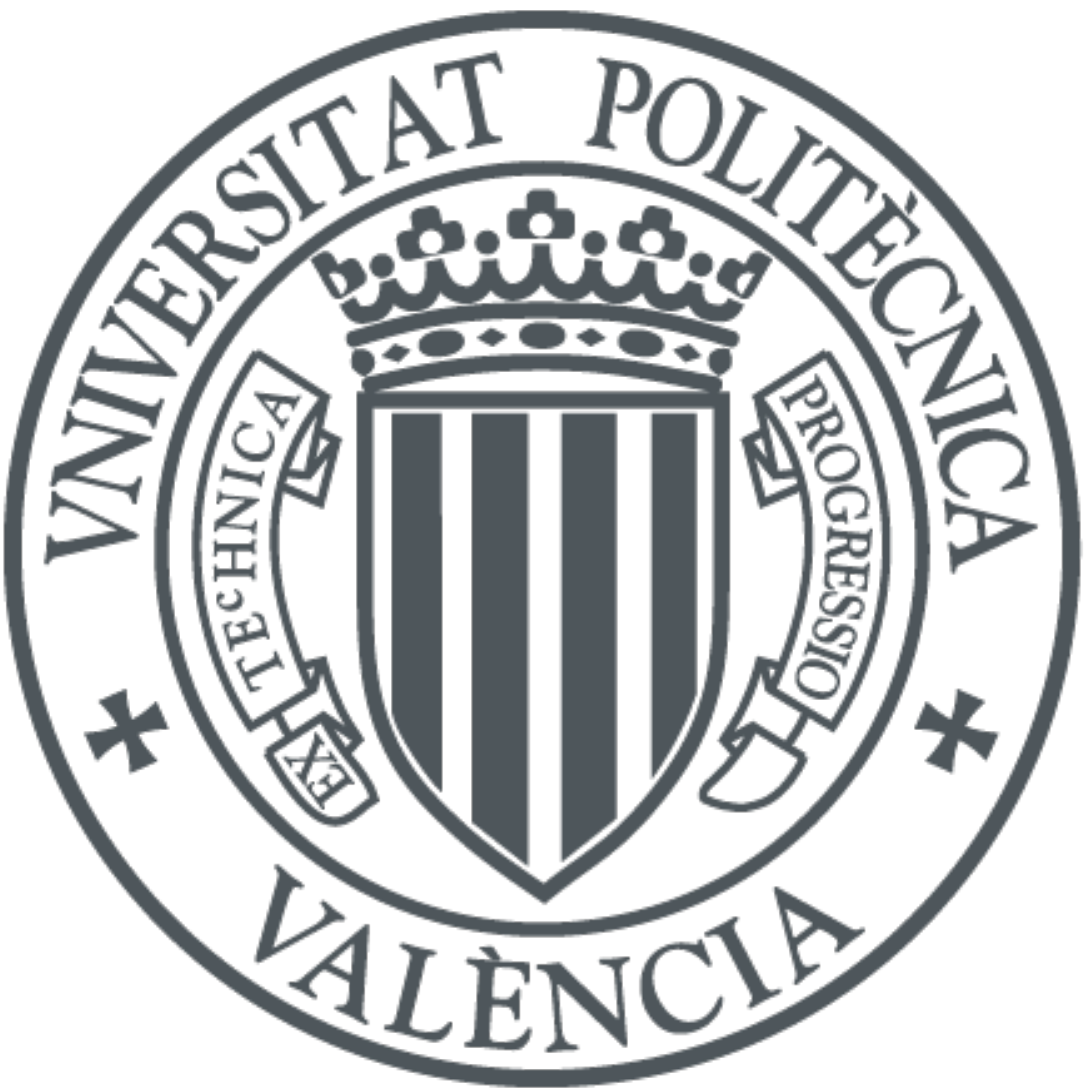

The final publication is available at

http://dx.doi.org/10.1016/j.enbuild.2012.10.040

Copyright Elsevier

Additional Information 


\title{
Experimental investigations on the influence of ice floating in an internal melt ice-on-coil tank
}

\author{
A. López-Navarro ${ }^{a}$, J. Biosca-Taronger ${ }^{\mathrm{a}}$, B. Torregrosa-Jaime ${ }^{\mathrm{a}}$, \\ J.M. Corberán ${ }^{a}$, J.L. Bote-García ${ }^{b}$, J. Payáa ${ }^{a}$ \\ ${ }^{a}$ Instituto de Ingeniería Energética IIE (Universidad Politécnica de Valencia) \\ Camino de Vera s/n, Edificio 8E cubo F 5 ${ }^{\mathrm{a}}$ planta, 46022 Valencia, Spain \\ ${ }^{\mathrm{b}}$ ACCIONA Infraestructuras S.A. Centro Innovación Tecnológica \\ C/ Valportillo II, 8, 28108 Alcobendas Madrid, Spain
}

\begin{abstract}
In this paper, the discharge of an experimental ice-storage tank is analyzed. The storage tank is an internal melt-ice-on-coil system. The discharge process has been studied for different mass flow rates and supply temperatures in the range from $10^{\circ} \mathrm{C}$ to $15^{\circ} \mathrm{C}$. The results indicate that once the ice breaks and floats towards the top of the tank, convection in the ice/water mixture is enhanced and the heat transfer fluid in the top coils becomes colder than in the bottom coils. Thus, an increase of the cooling power is generally observed around the ice-breaking point. Two correlations have been developed to reproduce the effect of the mass flow rate and supply temperature on the discharge duration and the mean cooling power.
\end{abstract}

Keywords: Thermal storage, experimental installation, PCM, ice melting, ice floating 
*Corresponding author. Tel: +34 963879910; Fax: +34 963877272;

E-mail address: jorpaher@iie.upv.es (J. Payá)

\begin{tabular}{|c|c|c|c|}
\hline \multicolumn{4}{|c|}{ NOMENCLATURE } \\
\hline $\operatorname{Re}$ & Reynolds number & Ste & Stefan number \\
\hline$\dot{m}$ & Mass flow rate, $\mathrm{kg} \mathrm{s}^{-1}$ & $C_{p}$ & Specific heat, $\mathrm{J} \mathrm{kg}^{-1} \mathrm{~K}^{-1}$ \\
\hline M & Mass of water/ice, $\mathrm{kg}$ & $\Delta \mathrm{h}$ & Melting enthalpy, $\mathrm{kJ} \mathrm{kg}^{-1}$ \\
\hline$\varepsilon$ & Effectiveness of the heat exchanger & NTU & $\begin{array}{l}\text { Number of heat transfer } \\
\text { units }\end{array}$ \\
\hline D & Diameter of the coils, $\mathrm{mm}$ & RMSE & Root-mean-square-error \\
\hline $\mathrm{R}$ & Thermal resistance, $\mathrm{K} \mathrm{W}^{-1}$ & HEX & Heat exchanger \\
\hline$\Delta \mathrm{T}^{\prime}$ & $\begin{array}{l}\text { Temperature difference brine/wall as } \\
\text { in Fig. } 4, \mathrm{~K}\end{array}$ & $\Delta \mathrm{T}$ & $\begin{array}{l}\text { Temperature difference } \\
\text { brine/PCM as indicated } \\
\text { in Fig. } 4, \mathrm{~K}\end{array}$ \\
\hline$\Delta \mathrm{t}$ & Duration of the latent heat process $(\mathrm{h})$ & $\dot{Q}$ & Thermal power, $\mathrm{W}$ \\
\hline PCM & Phase-change material & LHTS & $\begin{array}{l}\text { Latent heat thermal } \\
\text { storage }\end{array}$ \\
\hline $\begin{array}{l}\text { HTF } \\
\text { Subscr }\end{array}$ & $\begin{array}{l}\text { Heat transfer fluid } \\
\text { pts }\end{array}$ & TES & Thermal energy storage \\
\hline $\mathrm{h}$ & Heating & c & Cooling \\
\hline supply & Supply temperature & return & Return temperature \\
\hline fc & Forced convection inside the coils & $\mathrm{m}$ & Melting \\
\hline$N$ & Number of tests (9) & $\mathrm{t}$ & Tube \\
\hline
\end{tabular}




\section{INTRODUCTION}

The demand of refrigeration is continuously increasing due to global warming and to the increase of the energy requirements which derive from the population and economic growth. Especially in hot climates, the annual peak in the electricity grids occurs in the hottest day of the summer. In such climates, if the cooling load is shifted to night-time hours, cold storage systems can help reduce the energy costs [1-4] and reduce the overall $\mathrm{CO}_{2}$ emissions as the peak power loads are generally covered by fossil fuel thermal power plants. Although the total energy consumption in cold storage installations is generally higher than conventional systems due to the lower evaporation temperatures of the chiller [5-6] and to the additional heat transfer losses, the energy costs can be lowered particularly when rate structures with strong load-shifting incentives are applied [4].

Among the different thermal energy storage (TES) technologies, latent heat thermal storage (LHTS) systems are attracting an increasing interest mainly due to the high volumetric capacity. In cold storage systems, water is the most commonly used PCM in installations [7-8] among other reasons because of the high latent heat capacity, availability and low cost.

Experimental studies of encapsulated ice/water systems [9-11] have helped to better understand the melting and solidification processes, as well as the effects of natural convection. Nevertheless, in commercial-scale ice/water systems $[12,13]$ the volume of water is significantly bigger and the performance is also dependent on the design of the coils (shell and tube, spiral-shaped tubes, etc...).

In internal melt ice-on-coil systems, the brine flows through the coils and depending on the supply temperatures, the water around them freezes or melts. The discharge 
or melting of an internal melt ice-on-coil tank has several particularities and can be divided into several mechanisms, as mentioned by Zhu [14]:

- Quasi-concentric cylinder phase

- Eccentric phase

- Ice floating stage

- Ice pieces stage

As the water layer around the coils becomes bigger, eccentric phase models become preferable to quasi-concentric models due to the enhancement of the natural convection. When the ice detaches from the coils, it tends to float and in a final stage it breaks into pieces. Ice floating has a direct effect on the return temperatures of the tank, as shown by Wang [15] who studied the effect of the supply temperature and mass flow rate on the PCM temperature and outlet temperatures of an external meltice-on-coil tank.

In the case of internal melt ice-on-coil tanks, Zhu [14] validated a model with experimental data from Li $[16,18]$ who showed that, although the cooling power decreases progressively, at the end of the discharge process the cooling power can increase in a short time period due to the ice floating. Nevertheless, the internal melt ice-on-coil tanks which have been studied are generally of small capacities such as with single horizontal tubes $[18,19][20,21]$ or small tanks [22].

The aim of the present work is to make a full analysis of the discharge of an internal melt ice-on-coil tank with a significant capacity (around $172 \mathrm{kWh}$ ) and to better understand the effect of ice breaking on the heat transfer fluid temperatures. A novel point of this study is the analysis of the heat transfer fluid temperatures at different positions of a spiral-shaped coil immersed in an ice/water mixture. The combined analysis of the PCM and brine temperatures has helped to better comprehend the 
natural convection mechanisms. Furthermore, the duration and cooling power of the tests have been correlated to the operating conditions.

\section{EXPERIMENTAL SET-UP}

This paper presents experimental results of an ice-storage installation from the Polytechnic University of Valencia [23] (Spain). The installation (shown in Fig.1) has been designed to characterize latent heat thermal storage (LHTS) systems within a temperature range between $-10^{\circ} \mathrm{C}$ and $100^{\circ} \mathrm{C}$.

In order to charge and discharge the tank, an external heat sink and source is required. The heat transfer fluid (HTF) in the primary circuit is a $32 \%$ mass waterglycol mixture which flows through the ice-storage tank. Mass flow rates between $1000 \mathrm{~kg} / \mathrm{h}$ and $4000 \mathrm{~kg} / \mathrm{h}$ of the HTF are achieved by means of a variable-speed pump. The latter is a CRE 5-5 pump from GRUNDFOS, with a nominal power consumption of $750 \mathrm{~W}$.

The ice-storage system is a CALMAC ICEBANK tank 1098C. Fig. 2 shows a detailed scheme of the tank, which consists of 34 counter current spiral-shaped tubes immersed in the phase-change material (tap water/ice). Each tube has a total length of around $70 \mathrm{~m}$. In this study, the tank has been tested at a partial load by blocking the top 16 coils with plumbing accessories for polyethylene pipes. Thus, the HTF only circulates through the bottom 18 coils, which are the ones which are surrounded by water. 
The charging of the ice-storage tank requires supply temperatures of the HTF below $0^{\circ} \mathrm{C}$. This is achieved by providing chilled water/glycol from an $8 \mathrm{~kW}$ vapourcompression chiller to the heat exchanger $\mathrm{HEX}_{\mathrm{c}}$.

In the discharge tests of the ice-storage tank, a heat source is required to melt the ice. This is achieved using water from the building condensation ring (at around $22^{\circ} \mathrm{C}$ ) which heats the primary fluid by means of the plate heat exchanger $H E X_{\mathrm{h}}$. The supply temperature of the ice-storage tank is controlled by regulating the mass flow rate which flows through $\mathrm{HEX}_{\mathrm{h}}$ with the 3-way valve $\mathrm{V}_{\mathrm{h} 1}$.

The thermocouples inside the storage tank are all T-type and have been first calibrated in an ice/water mixture with an accuracy of $\pm 0.2 \mathrm{~K}$. The end of all thermocouples (reference junction end) have been placed together in an isotherm oil bath whose temperature is measured by means of a RTD thermal resistance PT100 $1 / 10$ DINB with an accuracy of $\pm 0.03 \mathrm{~K}$. This measurement procedure is explained in more detail in literature [24] and has enabled the calibration of the PCM temperature measurements with an accuracy of $\pm 0.2 \mathrm{~K}$ using functions from the National Institute of Standards and Technology (NIST) for the voltage/temperature conversion.

The thermocouples $T_{\mathrm{PCM} 1}-\mathrm{T}_{\mathrm{PCM} 6}$ shown in Fig. 1 have been placed to measure the PCM temperature in different vertical and radial positions. Additionally and as shown in Fig. 3, four thermocouples have been placed on the external surface of the coils and they have been isolated in order to measure the HTF temperature. The measurement principle is illustrated in Fig. 4. The thermocouples $T_{\mathrm{PCM} 7}$ and $\mathrm{T}_{\mathrm{PCM} 8}$ measure the PCM temperature between the adjacent rubes, as also indicated in Fig.

3.

A theoretical calculation of the thermal resistances shows that the insulation resistance is much higher than the rest of thermal resistances. Thus, the 
thermocouples which are attached to the tube wall practically measure the temperature of the HTF inside the coils, as can be inferred from Eq. (1):

$$
\frac{\Delta T^{\prime}}{\Delta T}=\frac{R_{f c}+R_{t}}{\sum_{i} R_{i}} \approx 0.031
$$

Where $\Delta T^{\prime}$ is the temperature difference between the brine and the external wall of the coil and $\Delta T$ is the temperature difference between the brine and the PCM, as shown in Fig. 4.

The temperature measurements are fully monitored by means of a datalogger Agilent 34970A and three 22 channels multiplexer HP 34901A with a recording interval of one minute. The instrumentation shown in Fig. 1 and Fig. 3 is located in one of the multiplexers, whereas the other 2 multiplexers monitor temperature measurements in the heating and cooling loops, and have been mainly used during the tuning of the installation.

The accuracy of the complete measurement equipment is summarized in Table 1. The supply and return temperatures of the heat transfer fluid have been measured with RTD thermal resistances PT100 1/10 DINB. The mass flow rate in the primary circuit is measured with a SIEMENS CORIOLIS flow meter.

\section{RESULTS AND DISCUSSION}

The discharge tests of the storage tank have been carried out under different operating conditions. Table 2 lists the discharge tests which have been performed, as 
well as the corresponding supply temperatures and mass flow rates of the HTF. The supply temperatures vary between $10.6^{\circ} \mathrm{C}$ and $14.6^{\circ} \mathrm{C}$ whereas the tested mass flow rates range between $2794 \mathrm{~kg} / \mathrm{h}$ and $4070 \mathrm{~kg} / \mathrm{h}$. Table 2 also shows the Reynolds and Stefan number of the tests based on the thermal properties which correspond to the mean temperature of the brine [25].

The use of spiral-shaped coils induce centrifugal forces in the HTF which have a stabilizing effect on the flow [26]. The critical Reynolds number has been calculated given the curvature of the coils in Fig. 2 and all the tested flow rates remain below the critical Reynolds number which is of 4790 . Hence, there is always a laminar flow in the HTF.

In the next paragraphs, the results are explained in detail for one typical charging test (D5). Firstly, the ice melting process is discussed by analyzing the temperature measurements of the phase-change material and of the heat transfer fluid. Secondly, the effect of the operating conditions is presented.

\subsection{Analysis of the ice melting process}

Fig. 5 shows the temperature measurements in the phase-change material $\left(\mathrm{T}_{\mathrm{PCM} 1}{ }^{-}\right.$ $\left.\mathrm{T}_{\mathrm{PCM}}\right)$ and in the supply and return of the HTF. The results follow similar tendencies to published literature of internal melt ice-on-coil systems [15].

The thermocouples in the external part of the tank $\left(\mathrm{T}_{\mathrm{PCM} 1}-\mathrm{T}_{\mathrm{PCM}}\right)$ are close to the coils and have hereby lower initial temperatures. The thermocouples in the center ( $\mathrm{TPCM}_{\mathrm{PC}}{ }^{-}$ $\left.\mathrm{T}_{\mathrm{PCM} 6}\right)$ are very far from the coils and have higher initial temperatures.

The central region ( $25 \mathrm{~min}$ to $250 \mathrm{~min}$ approximately) is the latent heat transfer region, where most of the thermocouples are measuring the melting temperature 
(around $0^{\circ} \mathrm{C}$ ). After $250 \mathrm{~min}$, the ice-breaking process starts and the tank enters progressively the sensible heat transfer region. Ice-breaking is very random and can be observed in Fig. 5 as temperature peaks. The thermocouples in the bottom ( $\mathrm{T}_{\mathrm{PCM} 3}$ and $\left.\mathrm{T}_{\mathrm{PCM} 6}\right)$ gradually increase their temperature with hardly any peaks. Once the ice separates from the coils from any part of the tank, the ice floats and is thus located in the top of the tank. Instead of showing a gradual increase as for the bottom thermocouples, the thermocouples in the top ( $\mathrm{T}_{\mathrm{PCM} 1}$ and $\mathrm{T}_{\mathrm{PCM} 4}$ ) present peaks whenever they receive any ice from lower layers. In the latter thermocouples, the temperature can decrease sharply if ice is collected around them.

Fig. 6 shows the temperatures of the HTF fluid as it flows through the spiral-shaped coils. In test D5, the mean supply temperature is $12.8^{\circ} \mathrm{C}$. As the HTF reaches the first turn of the spiral (centrifugal tubes), the HTF is cooled down to around $11^{\circ} \mathrm{C}$ due to the heat transfer with the ice/water which surrounds the coils. The HTF is slightly colder in the lower coils (row 2) than in the upper coils (row 16) because the HTF has more contact with the surrounding ice/water mixture. The centripetal tubes in Fig. 6 measure the outlet temperature of the heat transfer fluid, before reaching the return collector. After 200 min, they measure around $4^{\circ} \mathrm{C}$ which is slightly warmer than the return temperature.

Although ice-breaking is rather random, one key aspect which occurs in all of the tests is the ice floating. For instance, after 260 min in Fig. 6, it can be observed that the outlet temperature in the upper coils ( $\left.T_{\text {HTF turn } 1 \text { row } 17 \text { centripetal }}\right)$ suddenly decreases. At the same time, the outlet temperature in the lower coils ( $T_{H T F}$ turn 1 row 3 centripetal) increases, hereby demonstrating that ice has broken in the bottom and floated towards the top of the tank. Once the pieces of ice start to break and float, the tank 
enters the sensible heat transfer region and the temperatures rise more rapidly towards the supply temperature.

In all tests, the slope of the return temperature suddenly increases at the end of the latent heat transfer process. This moment (around 270 min in Fig. 5) matches rather well with the point when the last thermocouple warms up above the melting temperature of $0^{\circ} \mathrm{C}$.

\subsection{Effect of the operating conditions}

Fig. 7 and Fig. 8 show the cooling power which is achieved throughout the tests with different supply temperatures (Fig. 7) and mass flow rates (Fig. 8). In general terms, the higher the supply temperature and mass flow rate, the higher the cooling power, and consequently the duration of the discharge process shortens. The slope of the cooling power in the latent heat transfer region does not vary much, but the operating conditions tend to shift the cooling power curve upwards or downwards. When the ice starts to break and float, the outlet temperature increases and the cooling power decreases as also observed by Wang [15].

Two important aspects for any application are the cooling power and the duration of the discharge process. The mean cooling power has been calculated by means of Eq. (2) by integrating the thermal power which is exchanged instantaneously with the HTF.

$$
\overline{\dot{Q}}_{L H T S}=\frac{\int \dot{m}_{H T F} \cdot C_{p, H T F} \cdot\left|T_{\text {supply }}-T_{\text {return }}\right| d t}{\Delta t}
$$


Where $\Delta t$ is the duration of the latent heat transfer process. An empirical Eq. (3) has been developed to predict the effect of the operating conditions on the mean discharged power, and is valid in the tested range of operating conditions given in Table 2.

$$
\overline{\dot{Q}}_{L H T S}=0.013 \cdot\left(T_{\text {supply }}-T_{m}\right)^{0.938} \cdot \dot{m}_{H T F}{ }^{0.677}
$$

The parameters of Eq. (3) have been obtained by minimizing the root-mean-squareerror (RMSE) between the experimental and the predicted values.

$$
R M S E=\sqrt{\frac{\sum_{i=1}^{i=9}\left(\Delta t_{\text {exp }, i}-\Delta t_{\text {correlation }, i}\right)^{2}}{N}}
$$

The mean discharged power has been represented in Fig. 9 and provides complementary information to Figs. 7 and 8. The empirical Eq. (3) reproduces very accurately the mean cooling power as can be inferred from the low RMSE and from the mean error (2.4\%). In the tested range of conditions, the supply temperature has a more significant effect on the cooling power than the mass flow rate. The cooling power has a linear dependency on the supply temperature as can be inferred from Eq. (3) and from Fig. 9.

The duration of the tests is also an important point in any application. Experimentally, the duration of the latent heat transfer process $\Delta t$ has been obtained as the time which is required for the thermocouples $\left(\mathrm{T}_{\mathrm{PCM} 1}-\mathrm{T}_{\mathrm{PCM}}\right)$ to warm up above the melting temperature $\left(\mathrm{T}_{\mathrm{m}}=0^{\circ} \mathrm{C}\right)$. 
The duration of the tests can be predicted by assuming that the whole PCM is at the melting temperature $T_{m}$. In this case, the duration can be expressed as in Eq. (5).

$$
\Delta t=\frac{M \cdot \Delta h}{\dot{m} \cdot C_{p, H T F} \cdot\left(T_{\text {supply }}-T_{m}\right) \cdot \varepsilon(N T U)}
$$

Where $\mathrm{M}$ is the mass of water/ice (around $1876 \mathrm{~kg}$ ), $\Delta \mathrm{h}$ is the melting enthalpy (330 $\mathrm{kJ} / \mathrm{kg}$ ) and $\varepsilon$ is the effectiveness of the heat exchanger which depends on the number of heat transfer units and consequently on the mass flow rate. Thus, the empirical correlation shown in Eq. (6) has been developed to reproduce the effect of the mass flow rate and supply temperature on the discharge duration:

$$
\Delta t=2.29 \cdot 10^{-2} \cdot \frac{M \cdot \Delta h}{\dot{m}^{0.488} \cdot C_{p, H T F} \cdot\left(T_{\text {supply }}-T_{m}\right)}
$$

The parameters of Eq. (6) have also been obtained by minimizing the RMSE of the tests. The exponent of the mass flow rate (0.488) takes into account the effect of the mass flow rate on the effectiveness of the heat exchanger. Fig. 10 shows the impact of the mass flow rate and supply temperature on the duration of the discharge, as calculated by means of Eq. (5). The mean difference between the measurements and the correlation is $2.5 \%$ and the maximum deviation $5.7 \%$, hereby showing the good quality of the fitting. The higher the mass flow rate and the supply temperature, the shorter the discharge duration. As for the cooling power, the supply temperature has a bigger effect on the duration than the mass flow rate. 


\section{CONCLUSIONS}

In this work, the discharge of an ice-storage tank has been analyzed. Different tests have been performed to investigate the effect of the mass flow rate and supply temperature of the HTF. The following conclusions have been obtained:

- Ice breaking is rather random but nevertheless, follows a certain pattern. When the ice starts to break, it floats and the heat transfer fluid which returns from the upper coils, where most of the ice is collected, tends to decrease. On the contrary, the temperature of the heat transfer fluid in the lower coils tends to increase more rapidly.

- Convection is the predominant heat transfer mechanism in the phase-change material due to the significant density difference between water and ice. Ice floating is observed not only on the temperatures of the water/ice, but also on the return temperatures of the heat transfer fluid.

- The cooling power has a constant slope during the latent heat transfer process. A 3-parameter correlation has been developed and reproduces accurately the effect of the operating conditions on the mean cooling power. In the tested operating conditions $\left(\dot{m}=3000-4000 \mathrm{~kg} / \mathrm{h}, \mathrm{T}_{\text {supply }}=10-15^{\circ} \mathrm{C}\right)$, the supply temperature has a bigger and almost linear effect on the cooling power than the mass flow rate.

- The duration of the discharge process can be described by a two-parameter correlation, and is inversely proportional to the temperature difference between the supply temperature and the melting temperature. The tested 
mass flow rates have less impact on the duration than the supply temperatures.

\section{ACKNOWLEDGEMENTS}

The authors gratefully acknowledge ACCIONA Infraestructuras for the financing support and collaboration.

\section{REFERENCES}

[1] M.J. Sebzali, P.A. Rubini, Analysis of ice cool thermal storage for a clinic building in Kuwait, Energy Conversion and Management, 47 (2006) 3417-3434

[2] B. Rismanchi, R. Saidur, H.H. Masjuki, T.M.I. Mahlia, Energetic, economic and environmental benefits of utilizing the ice thermal storage systems for office building applications, Energy and Buildings, 50 (2012) 347-354

[3] J. Vetterli, M. Benz, Cost-optimal design of an ice-storage cooling system using mixed-integer linear programming techniques under various electricity tariff schemes, Energy and Buildings, 49 (2012) 226-234

[4] G.P. Henze, M. Krarti, M.J. Brandemuehl, Guidelines for improved performance of ice storage systems, Energy and Buildings, 35 (2003) 111-127

[5] B. Torregrosa-Jaime, J. Biosca-Taronger, J.C. Esteban-Matías, J. Payá, Feasibility study of a commercial ice storage installation for HVAC in a southern European building, Innostock 2012, The $12^{\text {th }}$ International Conference on Energy Storage

[6] F. Sehar, S. Rahman, M. Pipattanasomporn, Impacts of ice storage on electrical energy consumptions in office buildings, Energy and Buildings, 51 (2012) 255262

[7] ASHRAE, ASHRAE HANDBOOK, HVAC Applications, 2007

[8] I. Dincer, M.A. Rosen, Thermal Energy Storage, Systems and Applications, 2011 
[9] S.L. Chen, P.P. Wang, T.S. Lee, An experimental investigation of nucleation probability of supercooled water inside cylindrical capsules, Experimental Thermal and Fluid Science, 18 (1998) 299-306

[10] S.L. Chen, T.S. Lee, A study of supercooling phenomenon and freezing probability of water inside horizontal cylinders, International Journal of Heat and Mass Transfer, 41 (1998) 769-783

[11] I.W. Eames, K.T. Adref, Freezing and melting of water in spherical enclosures of the type used in thermal (ice) storage systems, Applied Thermal Engineering, 22 (2002) 733-745

[12] Available at http://www.calmac.com/, 2011

[13] Available at http://www.baltimoreaircoil.com, 2011

[14] Y. Zhu, Y. Zhang, Modeling of thermal processes for internal melt ice-on-coil tank including ice-water density difference, Energy and Buildings, 33 (2001) 363-370.

[15] B. Wang, X. Li, M. Zhang, X. Yang, Experimental Investigation of Discharge Performance and Temperature Distribution of an External Melt Ice-on-Coil Ice Storage Tank, HVAC\&R Research, 9 (2003) 291-308

[16] Q. Zhao, H. Li, J. Li, Experimental study of thermal properties of ice-on-coil thermal storage tank, Proceedings of National Symposium of HVAC \& R., 1998, pp. 227-231

[17] Q. Xu, Q. Zhao, H. Li, Experimental installation for thermal properties of ice-oncoil thermal storage tank, Proceedings of National Symposium of HVAC \& R., 1998, pp. 238-242

[18] M.A. Ezan, M. Ozdogan, A. Erek, Experimental study on charging and discharging periods of water in a latent heat storage unit, International Journal of Thermal Sciences, 50 (2011) 2205-2219

[19] A. Badr, An experimental study on ice formation around horizontal long tubes, International Journal of Refrigeration, 30 (2007) 789-797

[20] N. Kayansayan, M. Ali Acar, Ice formation around a finned-tube heat exchanger for cold thermal energy storage, International Journal of Thermal Sciences, 45 (2006) 405-418

[21] Y. Zhu, Y. Zhang, G. Li, F. Yang, Heat transfer processes during an unfixed solid phase change material melting outside a horizontal tube, International Journal of Thermal Sciences, 40 (2001) 550-563

[22 ]T. Koller, M. Zetzsche, H. Müller-Steinhagen, Design and operation of a small ice store, Eurosun 2008 
[23] A. López-Navarro, B. Torregrosa-Jaime, I. Martínez-Galván, J.L. Bote-García, J. Payá, Experimental analysis of a 173 kWh ice-storage tank, Innostock 2012, The $12^{\text {th }}$ International Conference on Energy Storage

[24] G.W. Burns, M.G. Scroger, G.F. Strouse, M.C. Croarkin, W.F. Guthrie, Temperature-electromotive force reference functions and tables for the letterdesignated thermocouple types based on the ITS-90, NIST Monograph, 175 (1993)

[25] A. Melinder, Properties of Secondary Working Fluids (Secondary Refrigerants or Coolants, Heat Transfer Fluids) for Indirect Systems, International Journal of Refrigeration (2010)

[26] VDI Gesellschaft Verfahrenstechnik und Chemieingenieurwesen, Vdi Heat Atlas, Springer (2010) 


$\begin{aligned} & \text { Supply and return temperature of } \\ & \text { the HTF (thermal resistances) }\end{aligned}$
$\begin{aligned} & \text { Calibrated T-type thermocouples } \\ & \text { inside the LHTS system }\end{aligned}$
$\begin{aligned} & \text { Coriolis flow meter } \\ & \text { Table 1. Accuracy of the measurement equipment }\end{aligned}$


\begin{tabular}{cccccccccc} 
Test ID number & D1 & D2 & D3 & D4 & D5 & D6 & D7 & D8 & D9 \\
\hline$\overline{\overline{\boldsymbol{m}}}$ (kg/h) & 4070 & 3519 & 2794 & 4065 & 3698 & 3138 & 4051 & 3486 & 2966
\end{tabular} \begin{tabular}{llllllllll}
\hline$T_{\text {supply }}\left({ }^{\circ} \mathrm{C}\right)$ & 14.6 & 14.4 & 14.1 & 12.8 & 12.8 & 12.7 & 10.8 & 10.6 & 10.6
\end{tabular} $\begin{array}{llllllllll}\text { Re } & 3117 & 2651 & 1987 & 3037 & 2583 & 2147 & 2757 & 2237 & 1924\end{array}$ \begin{tabular}{llllllllll} 
Ste $\left({ }^{*} \mathbf{1 0}^{3}\right)$ & 183 & 180 & 176 & 160 & 160 & 159 & 135 & 132 & 133 \\
\hline
\end{tabular} Table 2. Tests of the experimental campaign 
Fig. 1. Experimental set-up of the LHTS installation

Fig. 2. Scheme of the coils in the ice-storage tank

Fig. 3. Location of the thermocouples attached to the coils

Fig. 4. Measurement principle of the heat transfer fluid temperature

Fig. 5. Temperatures in the LHTS system (test D5)

Fig. 6. Heat transfer fluid temperatures (test D5)

Fig. 7. Mean cooling power for different supply temperatures

Fig. 8. Mean cooling power for different mass flow rates

Fig. 9. Effect of the operating conditions on the mean cooling power

Fig. 10. Effect of the operating conditions on the discharge duration 


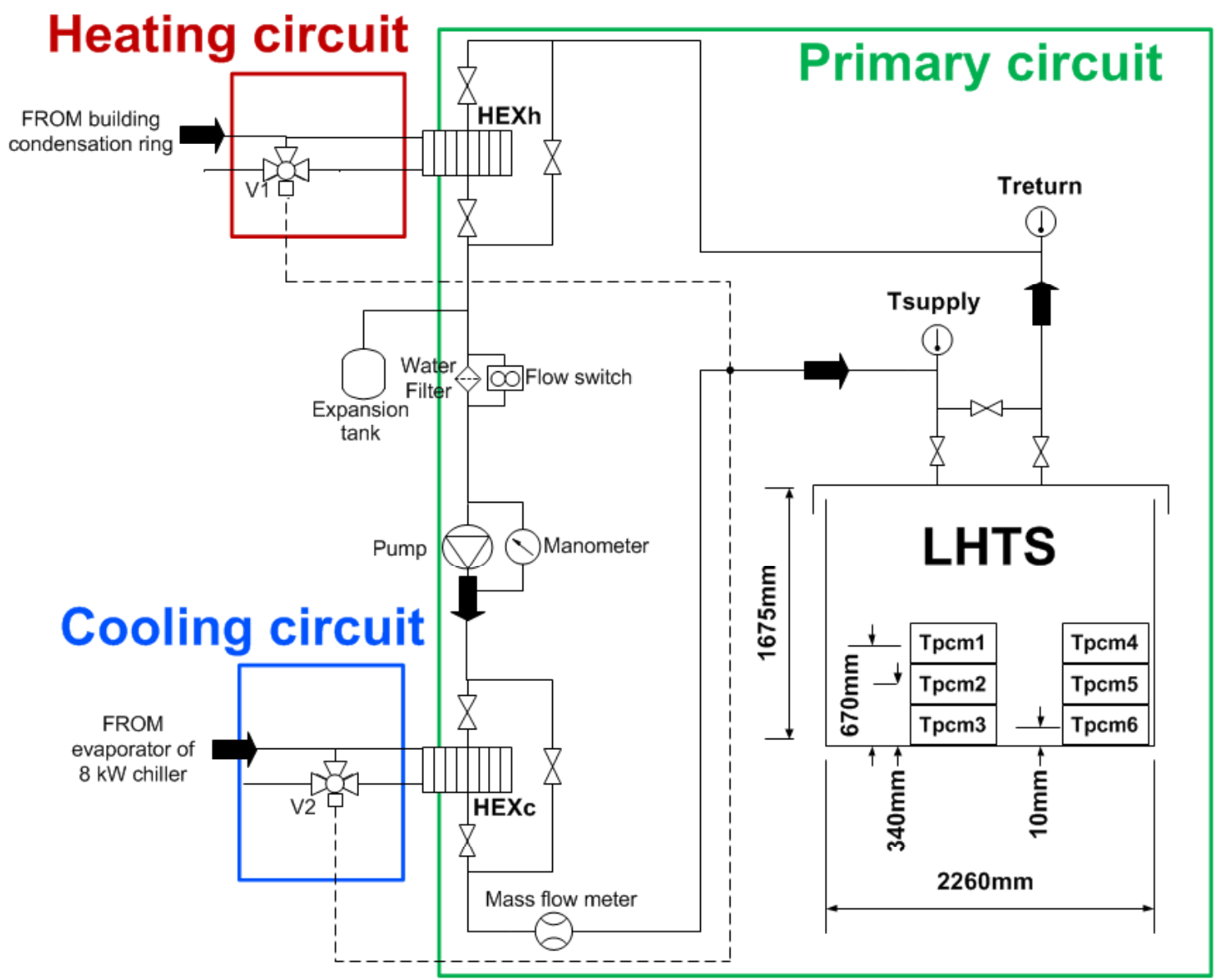




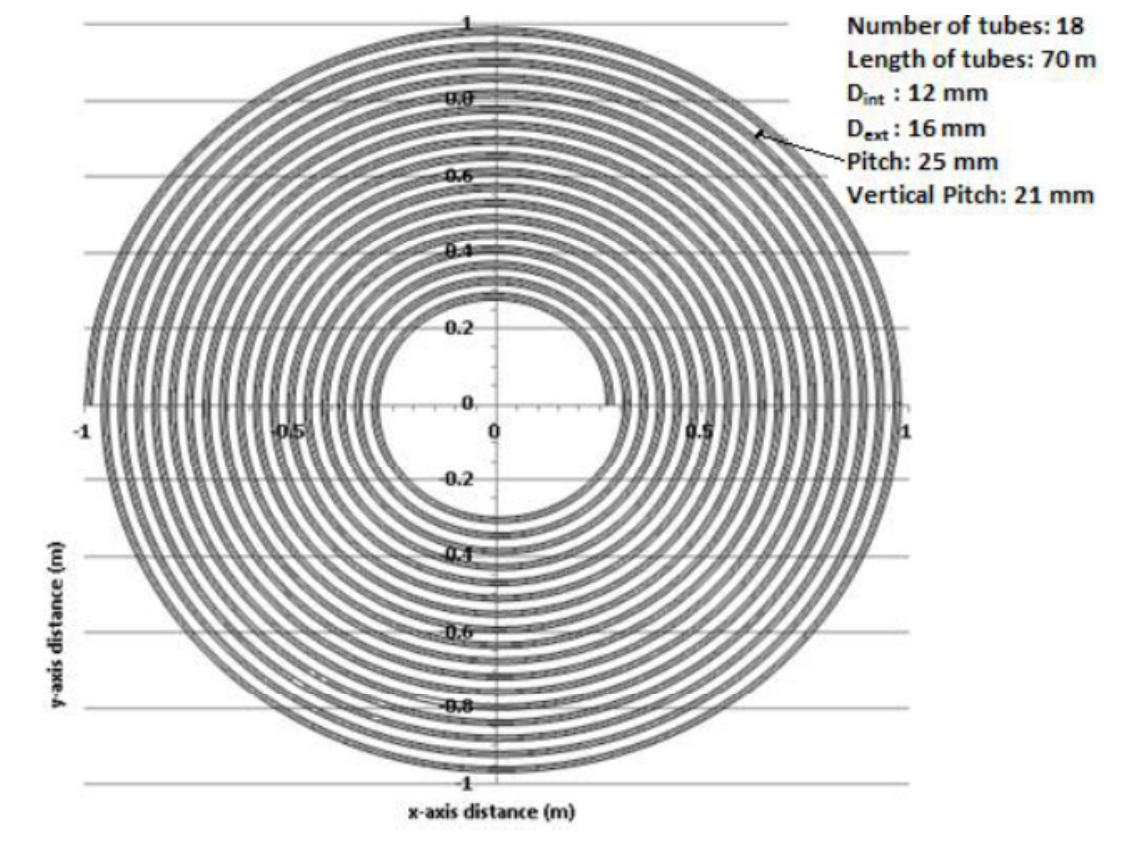

Number of tubes: 18
Length of tubes: $70 \mathrm{~m}$
$\mathrm{D}_{\text {int }}: 12 \mathrm{~mm}$
$\mathrm{D}_{\mathrm{m}}: 16 \mathrm{~mm}$

$x$-axis distance $(m)$

Figure 2
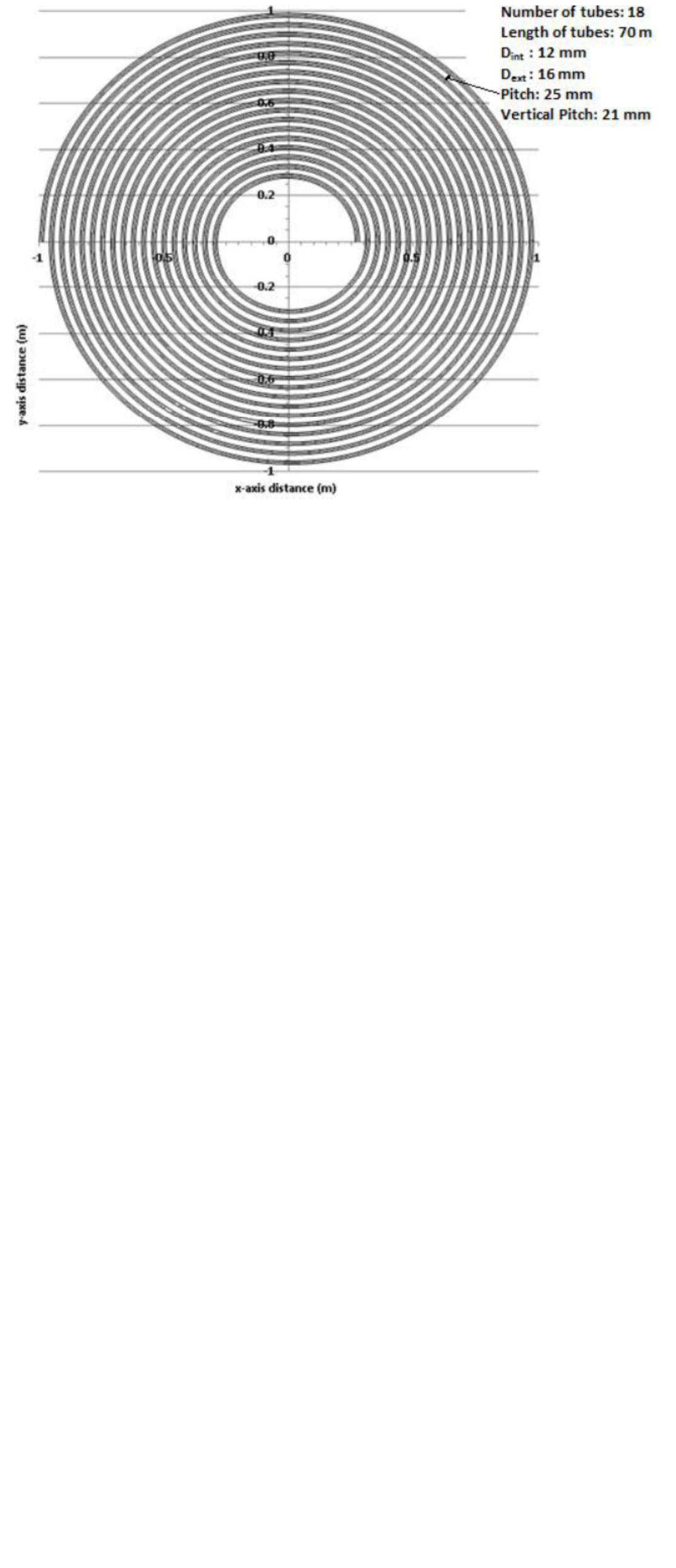

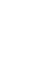

난. 
Figure 3

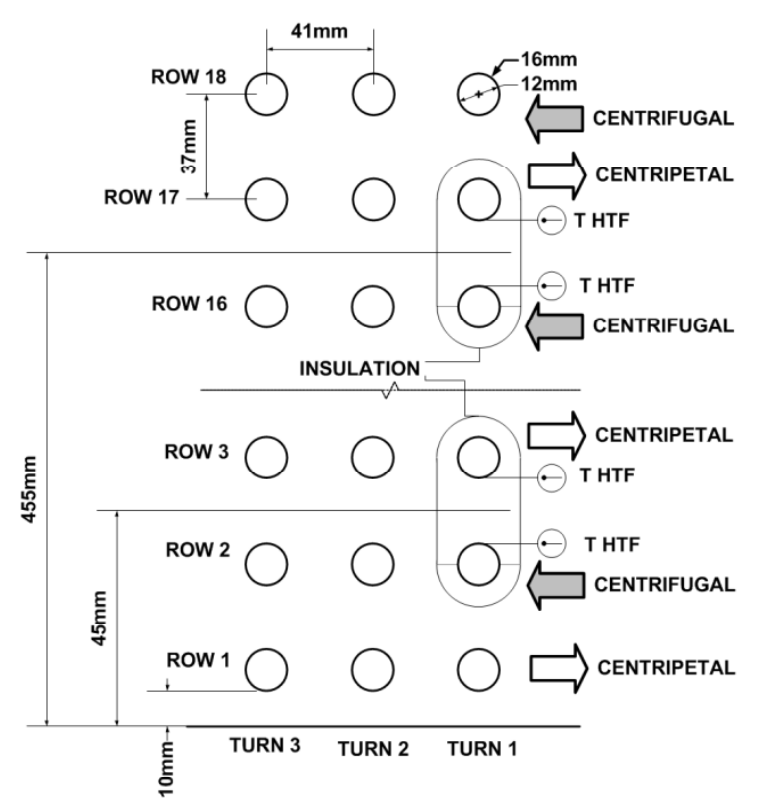


Figure 5

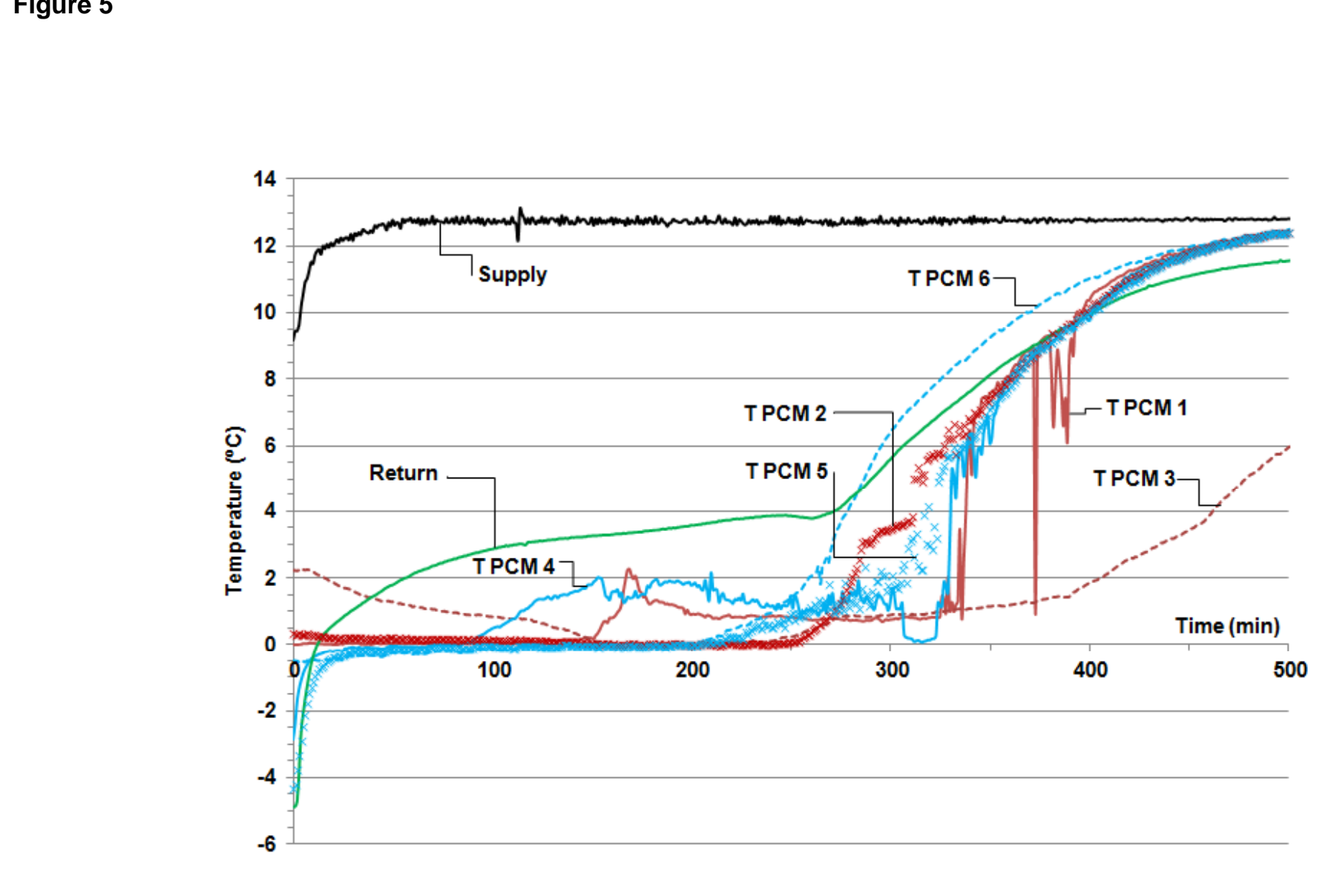

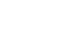
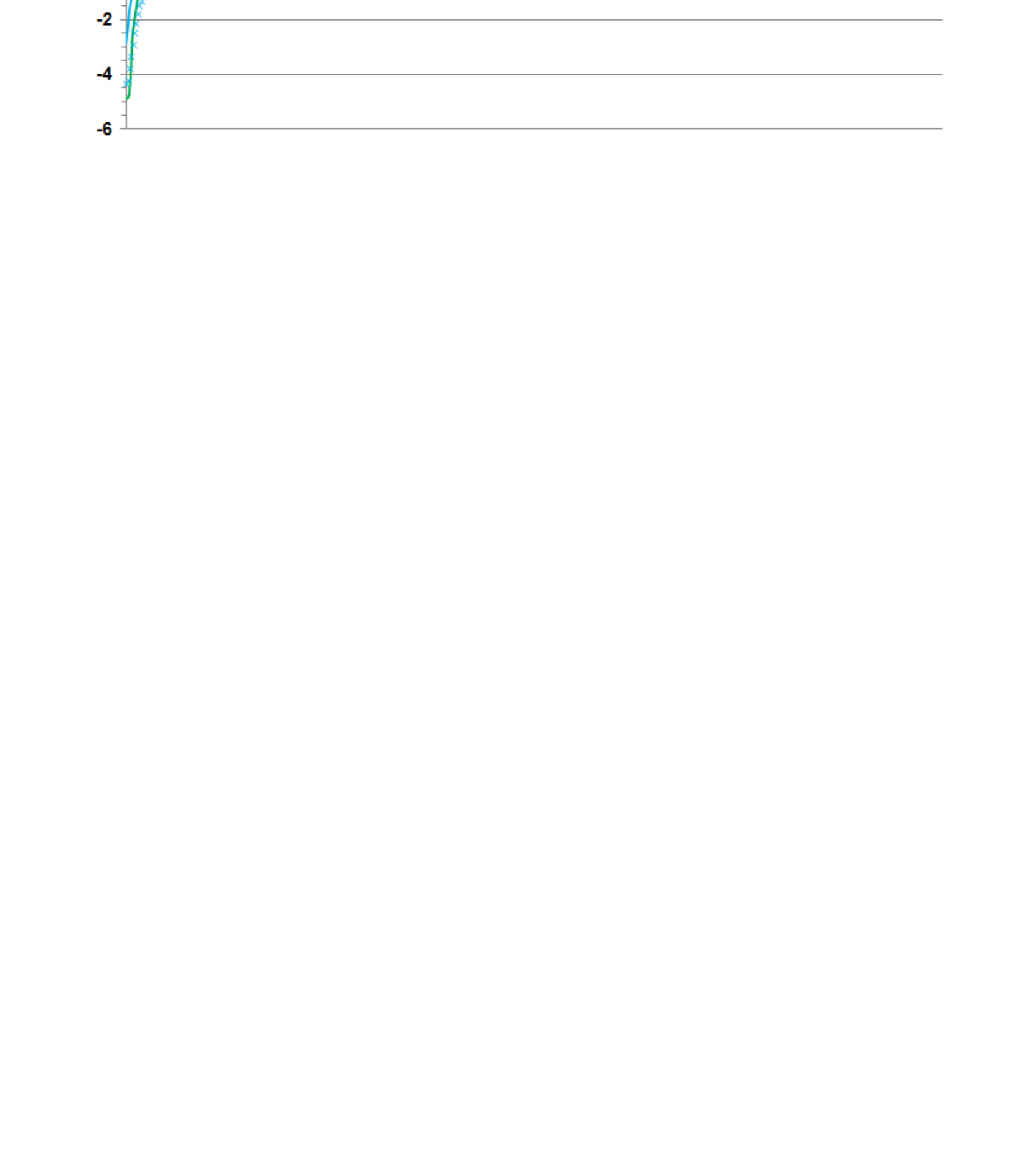
Figure 6

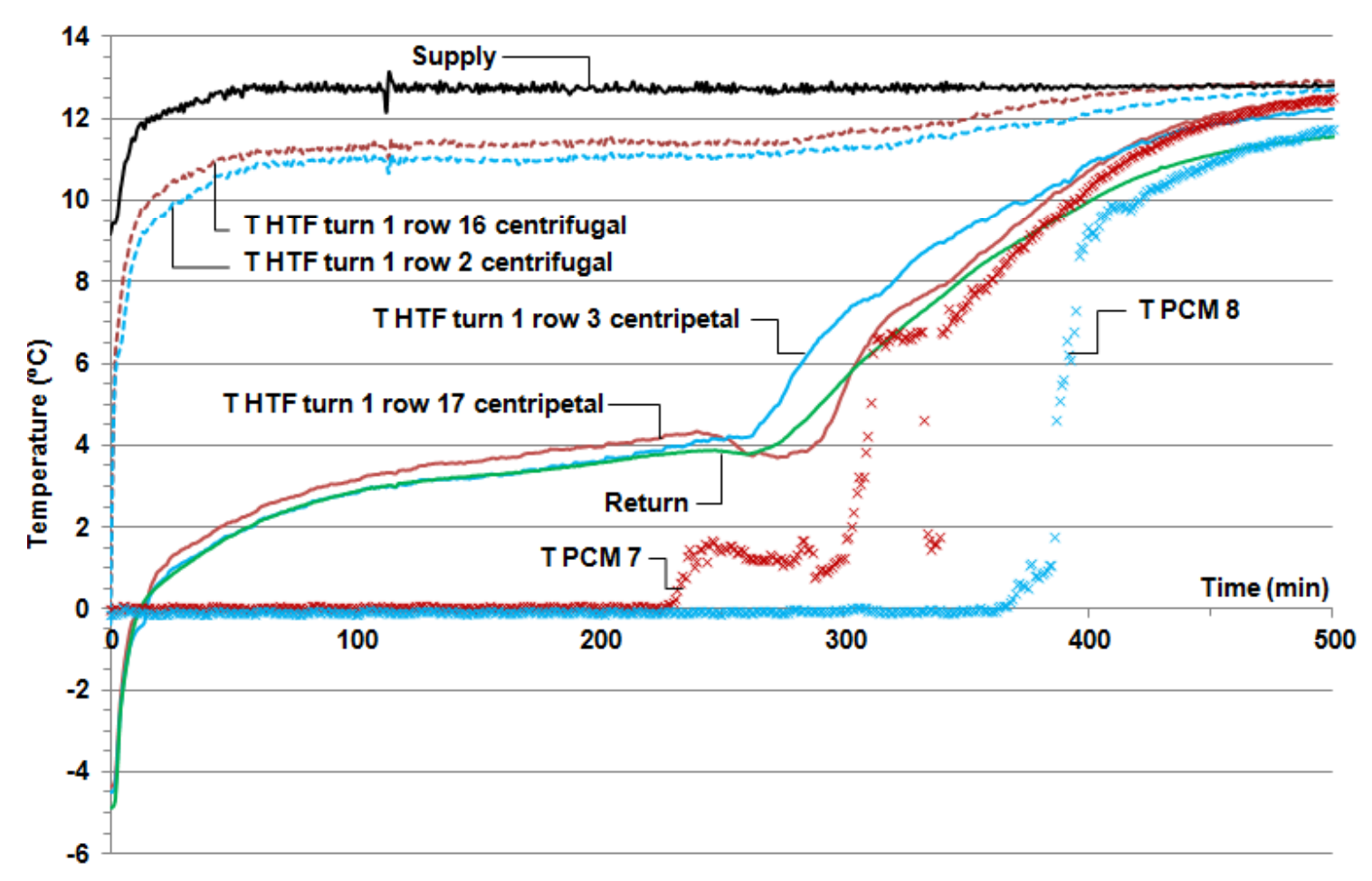


Figure 4

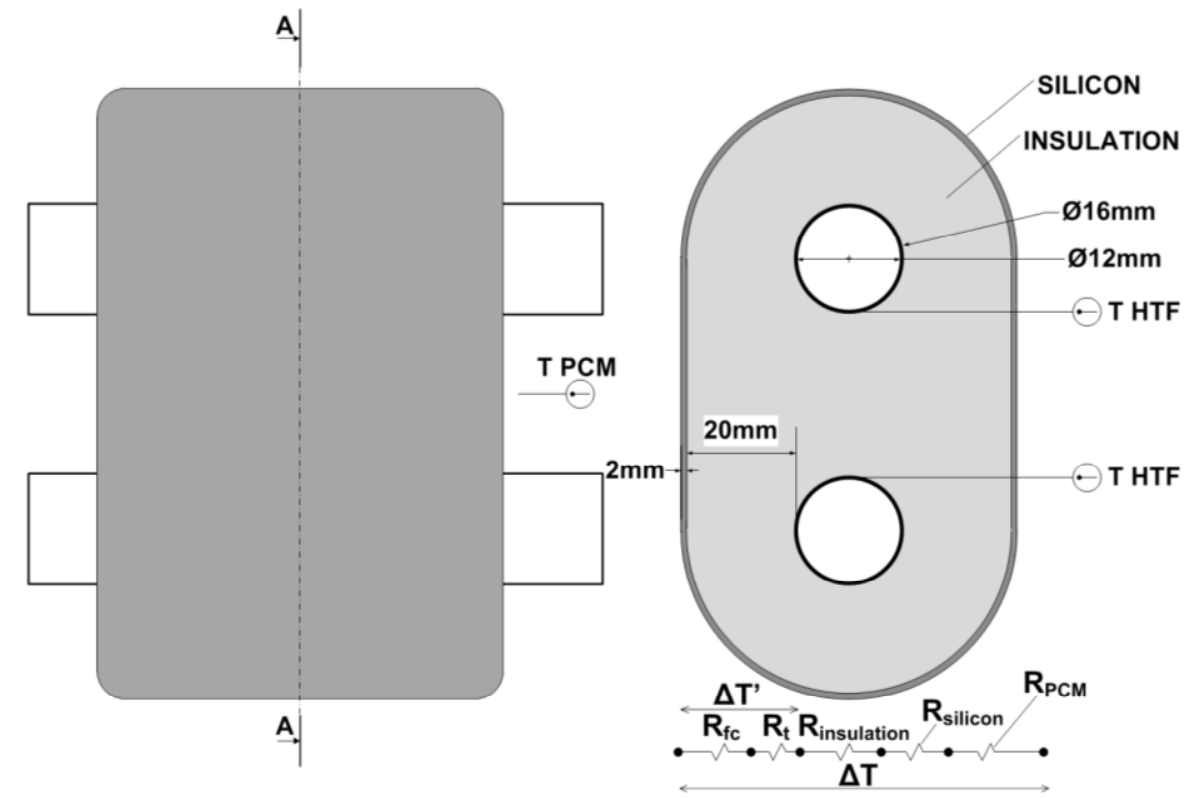


Figure 7

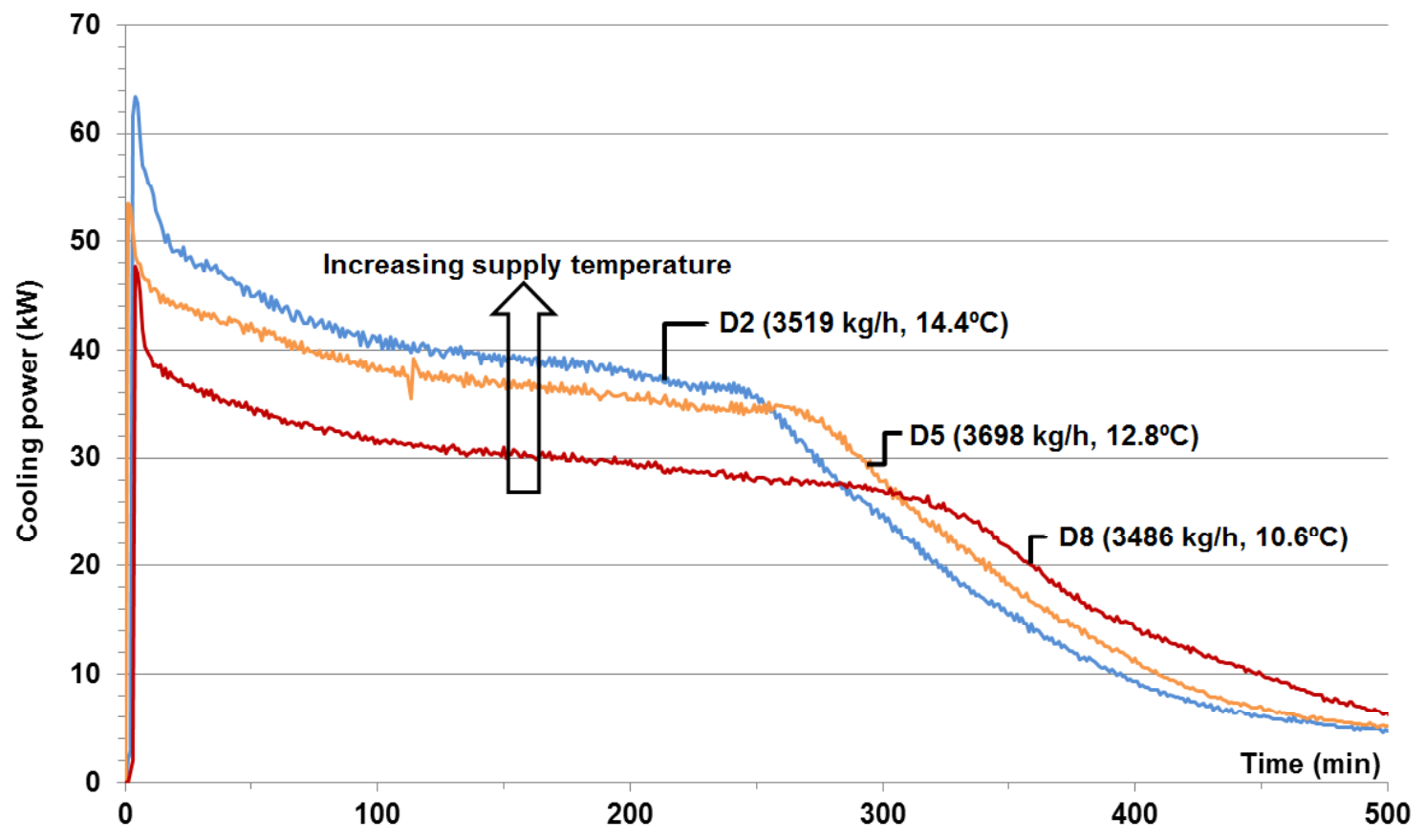


Figure 8

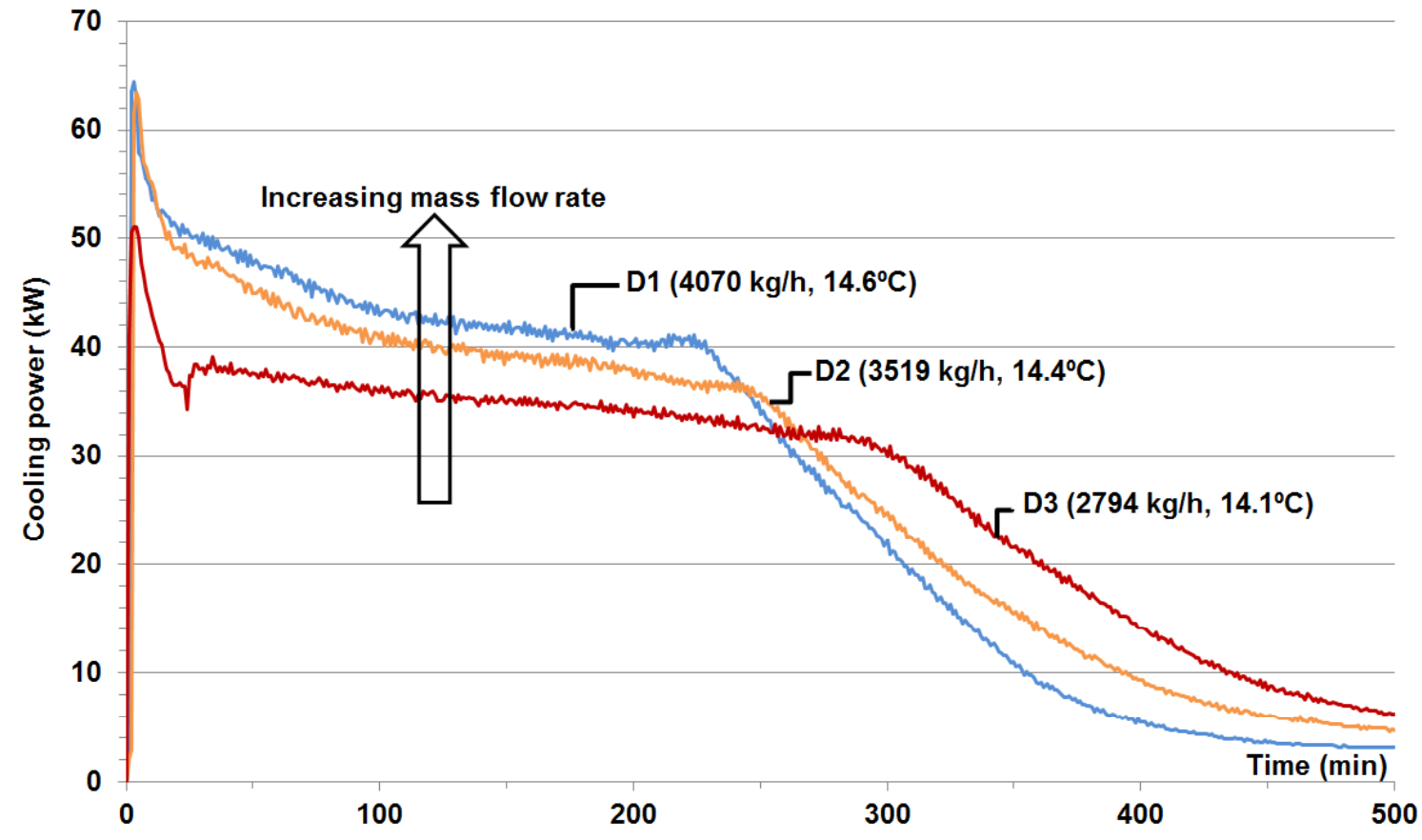


Figure 9

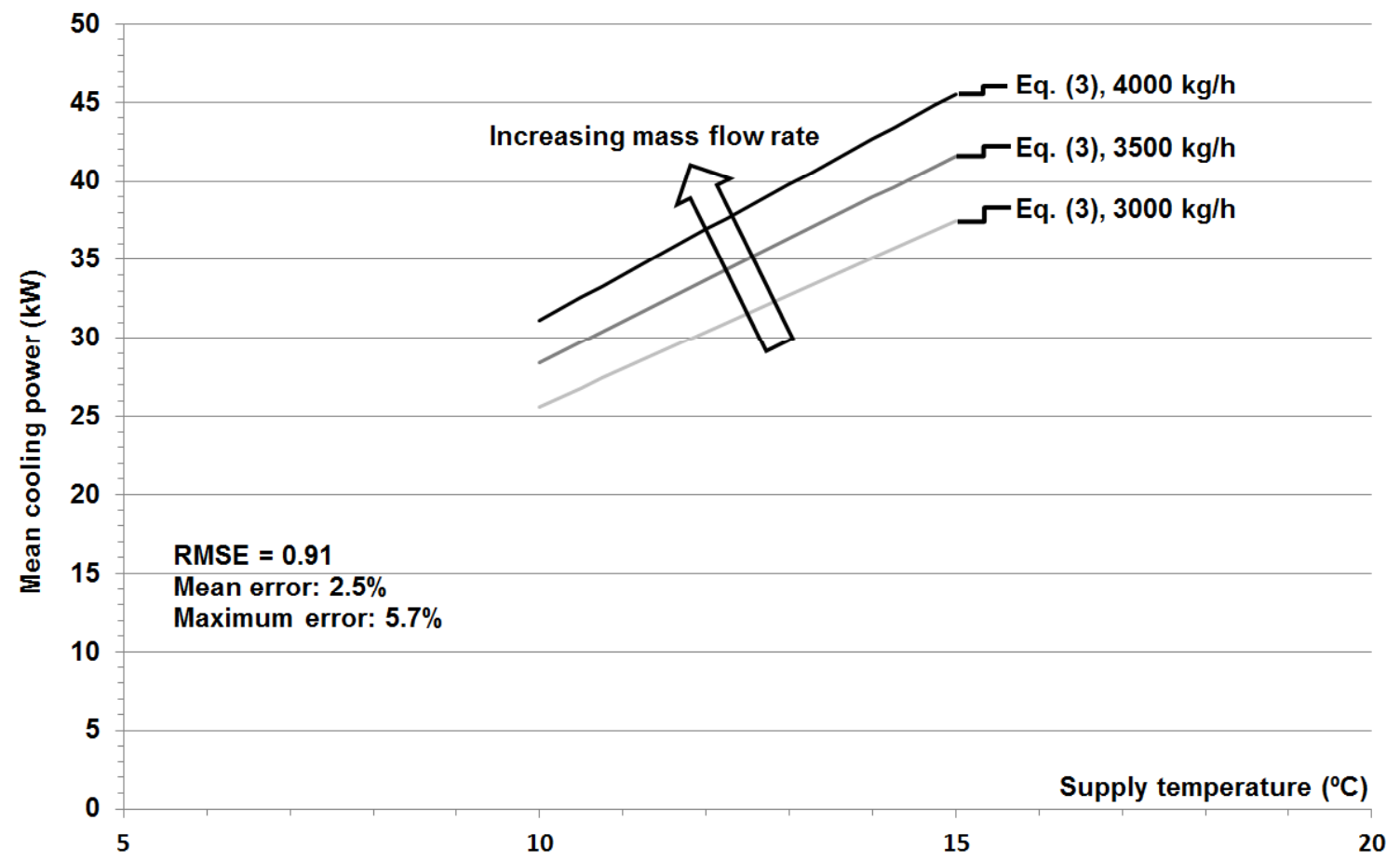




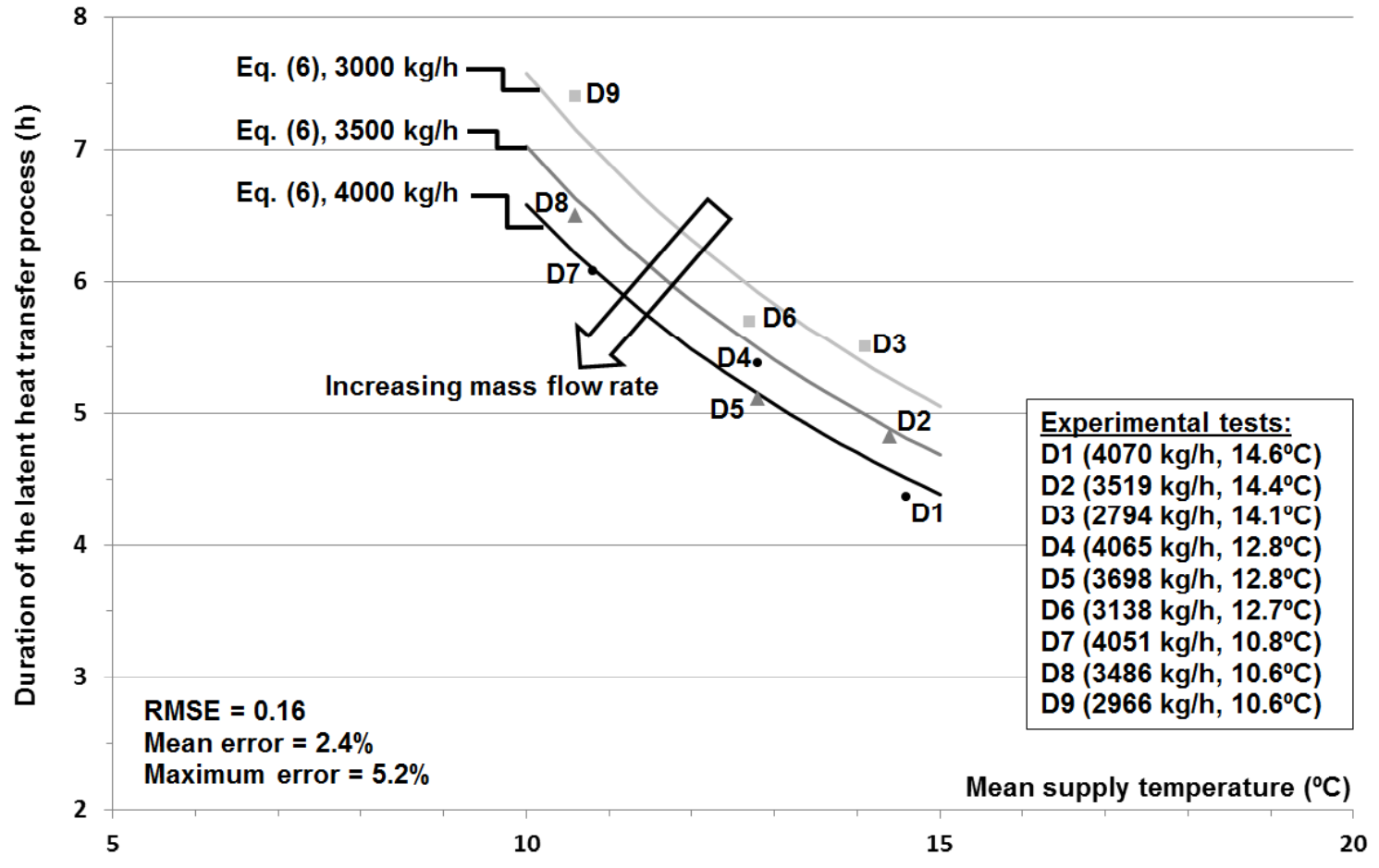


$>$ Discharge tests of an experimental ice-storage tank. > Temperature measurements of the phase-change material and of the heat transfer fluid. > Duration and cooling power correlated with mass flow rate and supply temperature. $>$ Ice breaking and floating is analyzed. 